\title{
Endophytic Actinomycetes: A Novel Source of Potential Acyl Homoserine Lactone Degrading Enzymes
}

\author{
Surang Chankhamhaengdecha, ${ }^{1,2}$ Suphatra Hongvijit, $2,3,4,5$ \\ Akkaraphol Srichaisupakit, ${ }^{1,2,3}$ Pattra Charnchai, ${ }^{2,3,4}$ and Watanalai Panbangred ${ }^{2,3,4,5}$ \\ ${ }^{1}$ Department of Biology, Faculty of Science, Mahidol University, Rama VI Road, Bangkok 10400, Thailand \\ ${ }^{2}$ Mahidol University-Osaka University Collaborative Research Center for Bioscience and Biotechnology (MU-OU:CRC), \\ Bangkok, Thailand \\ ${ }^{3}$ Faculty of Science, Mahidol University, Rama VI Road, Bangkok 10400, Thailand \\ ${ }^{4}$ Center of Excellence on Agricultural Biotechnology (AG-BIO/PERDO-CHE), Bangkok, Thailand \\ ${ }^{5}$ Department of Biotechnology, Faculty of Science, Mahidol University, Rama VI Road, Bangkok 10400, Thailand
}

Correspondence should be addressed to Watanalai Panbangred; watanalai.pan@mahidol.ac.th

Received 7 November 2012; Revised 28 December 2012; Accepted 2 January 2013

Academic Editor: Bertrand Aigle

Copyright (C) 2013 Surang Chankhamhaengdecha et al. This is an open access article distributed under the Creative Commons Attribution License, which permits unrestricted use, distribution, and reproduction in any medium, provided the original work is properly cited.

\begin{abstract}
Several Gram-negative pathogenic bacteria employ $N$-acyl-L-homoserine lactone (HSL) quorum sensing (QS) system to control their virulence traits. Degradation of acyl-HSL signal molecules by quorum quenching enzyme (QQE) results in a loss of pathogenicity in QS-dependent organisms. The QQE activity of actinomycetes in rhizospheric soil and inside plant tissue was explored in order to obtain novel strains with high HSL-degrading activity. Among 344 rhizospheric and 132 endophytic isolates, 127 (36.9\%) and $68(51.5 \%)$ of them, respectively, possessed the QQE activity. The highest HSL-degrading activity was at $151.30 \pm 3.1 \mathrm{nmole} / \mathrm{h} / \mathrm{mL}$ from an endophytic actinomycetes isolate, LPC029. The isolate was identified as Streptomyces based on 16S rRNA gene sequence similarity. The QQE from LPC029 revealed HSL-acylase activity that was able to cleave an amide bond of acyl-side chain in HSL substrate as determined by HPLC. LPC029 HSL-acylase showed broad substrate specificity from $\mathrm{C}_{6}$ - to $\mathrm{C}_{12}$-HSL in which $\mathrm{C}_{10} \mathrm{HSL}$ is the most favorable substrate for this enzyme. In an in vitro pathogenicity assay, the partially purified HSL-acylase efficiently suppressed soft rot of potato caused by Pectobacterium carotovorum ssp. carotovorum as demonstrated. To our knowledge, this is the first report of HSL-acylase activity derived from an endophytic Streptomyces.
\end{abstract}

\section{Introduction}

Bacterial pathogens infecting plants, animals, and humans cause a tremendous economic loss worldwide. Conventional treatments, such as application of antibacterial agents, significantly contribute to selection of resistant microorganisms as well as environmental contamination [1]. A number of concerns on using antibiotics have brought investigators to search for alternative strategies to combat with these pathogens. Attenuation of virulence phenotypes rather than killing of causative agents has gained an interest since this strategy does not introduce selective pressure which potentially leads to development of antibiotic-resistant bacteria [2]. Certain bacterial pathogens regulate their virulence by monitoring population density which is known as quorum sensing (QS) mechanism [3-5]. In Gram-negative bacteria, QS is often mediated by $N$-acyl-L-homoserine lactone (HSL) signal molecules [4]. Interference of HSL-dependent QS, commonly known as quorum quenching (QQ), has been demonstrated to be an effective antimicrobial strategy for controlling virulent pathogens [6-9]. QQ can be achieved by degradation of QS signal molecules by enzymatic digestion, significantly decreasing functions of signaling molecules. The QQ enzymes (QQEs) have been reported from several Grampositive bacteria including Arthrobacter sp. IBN110, Bacillus sp. 240B1, Geobacillus kaustophilus strain HTA426, Mycobacterium avium subsp. paratuberculosis K-10, Solibacillus silvestris StLB046 [10], and Streptomyces M664 [8]. However, 
there are differences in the catalytic spectrum among QQEs toward HSLs. In the search for QQE-producing bacteria, actinomycetes are of great interest since they possess an ability to produce and secrete various extracellular hydrolytic enzymes $[11,12]$. A number of actinomycetes have been isolated from several natural sources, including rhizospheric soil and plant tissues. Biological functions of actinomycetes predominantly depend on sources from which the bacteria are isolated. Natural resources in megabiodiversity with high selective pressure and microbial competition in tropical regions are well recognized as an important resource of new anti-microbial agents as well as QQE [13].

To date, the isolation of actinomycetes with high QQE activity from endophytes has never been reported. Screening for QQE-producing actinomycetes in this study showed the diversity and abundance of HSL-degrading actinomycetes from soil and plant tissues for the first time. The QQE from the high activity strain was shown to hydrolyze HSL with a broad range of chain length from $N$-hexanoyl-L-homoserine lactone $\left(\mathrm{C}_{6} \mathrm{HSL}\right)$ to $\mathrm{N}$-dodecanoyl-L-homoserine lactone $\left(\mathrm{C}_{12} \mathrm{HSL}\right)$; hence, this enzyme could be potentially used to attenuate virulence of a broad range of bacterial pathogens with different QS signal molecules.

\section{Materials and Methods}

2.1. Isolation of Rhizospheric and Endophytic Actinomycetes. Rhizospheric soil samples were collected from various provinces in Thailand, including Bangkok, Chanthaburi, Nongbualumpoo, Prachinburi, and Rayong provinces. To isolate rhizospheric actinomycetes, $1.0 \mathrm{~g}$ of soil was serially diluted in $4 \mathrm{~mL}$ of $0.85 \%$ normal saline solution (NSS). The appropriate dilution was spread on selective agars, which are Pridham's and water proline supplemented with $25 \mu \mathrm{g} / \mathrm{mL}$ nalidixic acid and $50 \mu \mathrm{g} / \mathrm{mL}$ cyclohexamide [14]. Isolates with typical actinomycetes colony morphology were selected for screening of HSL-degrading activity. In order to isolate endophytic actinomycetes, leaves, fruits, seeds, and stems of plant samples were collected from various regions in Thailand including Bangkok, Salaya botanical garden in Nakhon pathom, and Nam Nao national park in Phetchabun. All dirt was removed by running tap water. Samples were air-dried at room temperature for one week. Plant samples were cut into small pieces. Surface sterilization was performed by treating with $10 \%$ sodium hypochlorite (MERCK), $70 \%$ ethanol and followed by washing twice with sterile water. The samples were then air-dried and placed on water agar medium (containing only $1.5 \%$ agar) supplemented with $25 \mu \mathrm{g} / \mathrm{mL}$ nalidixic acid and $50 \mu \mathrm{g} / \mathrm{mL}$ cyclohexamide. Actinomycetes colonies were selected for further study.

2.2. HSL Inhibition Assay. Actinomycetes isolates were grown on Waskman's agar ( $1 \%$ glucose, $0.5 \%$ peptone, $0.5 \%$ meat extract, $0.3 \% \mathrm{NaCl}$, and $1.2 \%$ agar) for 3 days, subcultured in 301 broth $(2.4 \%$ starch, $0.1 \%$ glucose, $0.3 \%$ peptone, $0.5 \%$ meat extract, and $\left.0.3 \% \mathrm{CaCO}_{3}\right)$, and further incubated at $28^{\circ} \mathrm{C}$ with shaking for 6 days. Forty microliters of cell-free supernatant was mixed with an equal volume of
$40 \mu \mathrm{M} N$-decanoyl-L-homoserine lactone $\left(\mathrm{C}_{10} \mathrm{HSL}\right)$ in $0.1 \mathrm{M}$ Tris- $\mathrm{HCl} \mathrm{pH} \mathrm{6.8.} \mathrm{The} \mathrm{mixture} \mathrm{was} \mathrm{incubated} \mathrm{at} 28^{\circ} \mathrm{C}$ for $1 \mathrm{~h}$ with gentle agitation and the reaction was stopped by heating at $95^{\circ} \mathrm{C}$ for $5 \mathrm{~min}$. Then $10 \mu \mathrm{L}$ of reaction mixture was used to determine the remaining of $\mathrm{C}_{10} \mathrm{HSL}$ on a bioassay plate. For determination of HSL-degrading activity, Agrobacterium tumefaciens NTL4 (pZLR4) (kindly provided by Professor Stephen K. Farrand, Department of Crop Sciences and Microbiology, University of Illinois, USA) was used as a biosensor strain in bioassay to long-chain HSL $\left(\mathrm{C}_{8}\right.$ to $\left.\mathrm{C}_{12} \mathrm{HSL}\right)$ [15]. Chromobacterium violaceum CV026 (kindly provided by Professor Paul Williams, Department of Molecular Microbiology, University of Nottingham, $\mathrm{UK})$ was used to detect $N$-butanoyl-L-homoserine lactone $\left(\mathrm{C}_{4} \mathrm{HSL}\right), \mathrm{N}$-hexanoyl-L-homoserine lactone $\left(\mathrm{C}_{6} \mathrm{HSL}\right)$, and 3-oxohexanoyl-L-homoserine lactone (3-oxo- $\mathrm{C}_{6} \mathrm{HSL}$ ) [16]. Each reporter strain was cultivated overnight in nutrient broth (NB) and Luria-Bertani broth (LB), respectively. To determine HSL-degrading activity qualitatively, an overnight culture of the biosensor strain $(2.5 \mathrm{~mL})$ was mixed with $5 \mathrm{~mL}$ of agar. The mixture was overlaid on an $\mathrm{AB}$ minimal medium bioassay plate [17] supplemented with $40 \mu \mathrm{g} / \mathrm{mL}$ of 5-bromo-4-chloro-3-indolyl-D-galactopyranoside (X-gal) for A. tumefaciens NTL4 (pZLR4) and Luria-Bertani agar (LA) for C. violaceum (CV026). A well on an agar plate was made by punching with a cork borer $(\emptyset=0.4 \mathrm{~cm})$. Ten microliters of the heat inactivated reaction mixture was dropped in each well. All plates were incubated at $30^{\circ} \mathrm{C}$ overnight to allow color zone developing. Blue and purple color zones were developed around colonies of A. tumefaciens NTL4 (pZLR4) and $C$. violaceum (CV026), respectively, by the induction of the residual HSL in the reaction mixture. The residual amounts of HSL were calculated using relationship equations based on the color zone size and known amounts of HSL [6]. Relative activity of HSL-degrading enzyme was calculated by using the following formula: relative HSL-degrading activity $=($ HSL-degrading activity/initial amount of substrate $) \times$ 100. For quantitative HSL-degrading activity determination, bioassay agar medium in the plate was cut into separated slices across the plate $(1 \mathrm{~cm}$ in width). Five microliters of the reaction mixture was added to one end of an agar slice and then the culture of biosensor strain at an $\mathrm{OD}_{600}$ of 1 was progressively spotted $(0.6 \mu \mathrm{L}$ per spot) at further distances from the loaded reaction mixture. The last induced color colony to the origin of the reaction mixture sample in each agar slice was measured. Amounts of HSL in the reaction mixture were determined based on relationship equation of adding known amounts of HSL to the bioassay slices and determining the distance of the color colony from the origin. HSL-degrading activity reported as nmole/h was calculated from subtraction of the initial amount of HSL substrate with leftover amount from the enzymatic digestion.

2.3. Strain Identification. The $16 S \quad r R N A$ gene of isolate LPC029 was amplified using conserved primers [18]. PCR was performed for 30 cycles at $95^{\circ} \mathrm{C}$ for 45 seconds, $45^{\circ} \mathrm{C}$ for 45 seconds, and $72^{\circ} \mathrm{C}$ from 1.5 minutes. The PCR product was sequenced by the dideoxy chain-termination method [19]. 
2.4. Preparation of Partially Purified HSL-Degrading Enzyme. The endophytic isolate LPC029 was harvested after 6 days of culture in $1,000 \mathrm{~mL} 301$ medium by centrifugation at $4^{\circ} \mathrm{C}$ $(10,000 \mathrm{~g})$ for $10 \mathrm{~min}$. The supernatant was filtered through a $0.45 \mu \mathrm{m}$ membrane and stored at $4^{\circ} \mathrm{C}$. Ammonium sulfate was added to the culture supernatant to achieve $60 \%$ saturation and the solution was left at $4^{\circ} \mathrm{C}$ for $16 \mathrm{~h}$. The precipitate was collected by centrifugation, dissolved, in $6 \mathrm{~mL}$ of $20 \mathrm{mM}$ sodium phosphate buffer $\mathrm{pH}$ 7.0, and dialyzed (dialysis tubing, MW cut-off $10 \mathrm{kDa}$; Sigma, USA) overnight against the same buffer. The dialyzed sample was then collected and stored at $4^{\circ} \mathrm{C}$.

2.5. HSL Degradation Assay. $\mathrm{C}_{10} \mathrm{HSL}$ was used as a substrate in the determination of hydrolytic products of the HSLdegrading enzyme. Substrates were prepared as a stock solution at $8 \mathrm{mM}$ in $80 \%$ ethanol. The HSL-degrading product was analyzed by mixing $13 \mu \mathrm{g}$ of the partially purified HSLdegrading enzyme and $350 \mathrm{mM}$ of $\mathrm{C}_{10} \mathrm{HSL}$ in $700 \mathrm{~mL}$ of $20 \mathrm{mM}$ sodium phosphate buffer $\mathrm{pH}$ 7.0. After incubation at $30^{\circ} \mathrm{C}$ for $16 \mathrm{~h}$, the reaction mixture was extracted three times with equal volumes of ethyl acetate. The organic phase was evaporated to dryness at $40^{\circ} \mathrm{C}$ by a rotary evaporator. The dried sample was dissolved in $50 \mu \mathrm{L}$ of HPLC grade methanol. Five microliters of HSL-degraded products was introduced onto Shiseido Capcell Pak C18 $(4.6 \times 250 \mathrm{~mm}$ I.D.; particle size $5 \mu \mathrm{m}$ ) previously equilibrated with $10 \%$ acetonitrile. The elution was performed with linear gradient of $10-90 \%$ acetonitrile, at a flow rate of $1 \mathrm{~mL} / \mathrm{min}$ under the following condition: $10 \%$ acetonitrile from 0 to $8 \mathrm{~min}$; linear gradient to $90 \%$ acetonitrile from 8 to $35 \mathrm{~min}$. Homoserine lactone $(3.5 \mathrm{mM})$ and $35 \mathrm{mM}$ of $\mathrm{C}_{10} \mathrm{HSL}$ were used as a standard. HPLC chromatogram of the products was analyzed by diode array detector with UV ranging from 200 to $280 \mathrm{~nm}$ (Agilent 1200 HPLC). To check substrate specificity, HSLacylase was reacted with different HSL-substrates including $\mathrm{C}_{4} \mathrm{HSL}, \mathrm{C}_{6} \mathrm{HSL}$, 3-oxo- $\mathrm{C}_{6} \mathrm{HSL}$, 3-oxo- $\mathrm{C}_{8} \mathrm{HSL}, \mathrm{C}_{10} \mathrm{HSL}$, and $\mathrm{C}_{12} \mathrm{HSL}$. Reaction mixture was composed of $0.4 \mathrm{mM}$ each of HSL substances in $20 \mathrm{mM}$ sodium phosphate at $\mathrm{pH} 7.0$ and $2 \mu \mathrm{g}$ of the partially purified HSL-degrading enzyme in $50 \mu \mathrm{L}$. The mixture was incubated at $30^{\circ} \mathrm{C}$ for $1 \mathrm{~h}$. The HSL-substrate that remained in the reaction mixture was determined by the bioassay method as described above.

2.6. In Vitro Pathogenicity Assay. The assay was performed as described by Burr et al. [20]. The potatoes' tubers of about the same size were washed with tab water and pretreated in $5 \%$ sodium hypochlorite (Merck) for 10 min then soaked with sterile water. The tubers were dried in a laminar flow cabinet. P. carotovorum ssp. carotovorum $(P c c)$ was cultured in $50 \mathrm{ml}$ of $\mathrm{LB}$ broth at $30^{\circ} \mathrm{C}$ overnight. The culture at $\mathrm{OD}_{600}$ of 1 was further serially diluted with $0.85 \%$ NSS to $10^{-5}$. Ten microliters of 100,000 -folded dilution of Pcc (ca. $1000 \mathrm{cfu} / 10 \mu \mathrm{L}$ ) was mixed with $2 \mu \mathrm{g}$ of partially purified HSLdegrading enzyme. The reaction was then further incubated at $30^{\circ} \mathrm{C}$ for $1 \mathrm{~h}$ and was inoculated into a potato tuber. A two-hundred-microliter pipette tip was used to punch a hole of $22 \mathrm{~mm}$ in depth, 2 holes per tuber. The two holes in each potato tuber were each filled with $0.85 \%$ NSS (negative control), 1000 cells of $P c c$ (positive control), the mixture of $P c c$ and HSL-acylase, and HSL-acylase alone. The inoculated potato tubers were further sealed with a sterilized sticker. To make a moisture condition, the tubers were wrapped with aluminum foil and sterile moist towels. The wrapped-potato tubers were incubated in a closed box at $30^{\circ} \mathrm{C}$ for 3 days.

\section{Results and Discussion}

3.1. Screening of HSL-Degrading Actinomycetes and HSLDegrading Activity. The abundance and diversity of HSLdegrading actinomycetes isolated from soil and plant tissues were assessed. They were isolated on the basis of their typical morphologies (filamentous growth, spore chain, and several types of convex and margin colonies on selective medium) according to Bergey's Manual of Systematic Bacteriology [21]. While 344 actinomycetes could be isolated from 43 rhizospheric soil samples, only 132 isolates were obtained from 64 plant samples. Among these actinomycetes isolates, the number of isolates with HSL degrading activity was found in higher frequency in endophytic isolates (51.5\%) than in rhizospheric isolates (36.9\%) (Table 1). While several previous studies have indicated the HSL-degrading activity in soil bacteria $[8,22,23]$, this study is the first report of such activity in endophytic actinomycetes. The evolution race for survival in tropical ecosystem reinforces strong competition among organisms, which may result in a plethora of chemical molecules [24], and enzymes [11, 12] with biological functions. Consequently, there is a high probability that microorganisms associated with tropical plants might be a source of bioactive compounds and enzymes. Among our isolates with HSL-degrading activity, 4 rhizospheric actinomycetes (PS032, SWP036, SWP042, and SWP043) and 5 endophytic actinomycetes (LPC026, LPC029, PC005, PC052, and PC053) were found to be the potential strains in HSL degrading as they were able to degrade HSL of greater than 96.9\% relative activity (Table 1). Quantitative measurement of enzymatic activity among these 9 isolates showed that isolate LPC029 from Gmelina arborea Roxb. possessed the highest HSL-degrading activity at $151.30 \pm 3.1 \mathrm{nmole} / \mathrm{h} / \mathrm{mL}$ (Table 2). Strain LPC029 was later identified with $16 \mathrm{~S} r R N A$ gene sequence (GenBank accession number KC153060) to be closely related to S. globisporus at $99 \%$ homology. The presence of HSL-degrading activity in both soil and plant isolates may be due to their common need of HSL-degraded product as carbon and energy sources [25] and for competition with other microbes to protect their ecological niche [26]. In addition, endophytic bacteria have previously been reported to be involved in several biological functions such as promoting plant growth, biocontrol agents, and phytoremediation [24, 27-29]. These functions stem from the production of their natural compounds and antipathogen metabolites inside the host plant [29].

3.2. HPLC Analysis of $C_{10}$ HSL Hydrolysis by LPC029 HSLDegrading Enzyme. The products of HSL degradation by enzyme from LPC029 were analyzed by HPLC after ethyl 
TABLE 1: Relative HSL-degrading activity of actinomycetes isolated from rhizospheric and endophytic samples.

\begin{tabular}{|c|c|c|c|c|c|c|c|c|}
\hline \multirow{2}{*}{ Location } & \multirow{2}{*}{ No. of isolates } & \multicolumn{7}{|c|}{ Relative HSL-degrading activity* (\%) } \\
\hline & & 0 & $>0-50$ & $>50-75$ & $>75-87.5$ & $>87.5-93.8$ & $>93.8-96.9$ & $>96.9-100$ \\
\hline \multicolumn{9}{|l|}{ Rhizospheric samples } \\
\hline Bangkok & 278 & 182 & 54 & 16 & 11 & 8 & 4 & 3 \\
\hline Chanthaburi & 13 & 6 & 5 & 0 & 0 & 1 & 1 & 0 \\
\hline Nongbualumpoo & 3 & 2 & 0 & 0 & 0 & 0 & 0 & 1 \\
\hline Prachinburi & 27 & 12 & 9 & 3 & 3 & 0 & 0 & 0 \\
\hline Rayong & 23 & 15 & 8 & 0 & 0 & 0 & 0 & 0 \\
\hline Total & 344 & 217 & 76 & 19 & 14 & 9 & 5 & 4 \\
\hline \multicolumn{2}{|c|}{ Total (percentage) } & $217(63.1 \%)$ & \multicolumn{6}{|c|}{$127(36.9 \%)$} \\
\hline \multicolumn{9}{|c|}{ Endophytic samples } \\
\hline Bangkok & 43 & 29 & 12 & 0 & 1 & 1 & 0 & 0 \\
\hline Nakhonpathom & 29 & 20 & 8 & 1 & 0 & 0 & 0 & 0 \\
\hline Phetchabun & 60 & 15 & 25 & 0 & 10 & 1 & 4 & 5 \\
\hline Total & 132 & 64 & 45 & 1 & 11 & 2 & 4 & 5 \\
\hline \multicolumn{2}{|c|}{ Total (percentage) } & $64(48.5 \%)$ & \multicolumn{6}{|c|}{$68(51.5 \%)$} \\
\hline
\end{tabular}

TABLE 2: Quantitative HSL-degrading activity of isolates with high efficiency of HSL degradation.

\begin{tabular}{lcc}
\hline Source & Name of isolate & HSL-degrading activity (nmole/h/mL) \\
\hline Rhizosphere soil, Nongbualumpoo & PS032 & $143.42 \pm 1.5$ \\
Rhizosphere soil, Bangkok & SWP036 & $144.67 \pm 2.1$ \\
Rhizosphere soil, Bangkok & SWP042 & $144.37 \pm 1.5$ \\
Rhizosphere soil, Bangkok & SWP043 & $144.26 \pm 1.3$ \\
Leaf of Ta khram (Garuga pinnata Roxb.) & LPC026 & $146.45 \pm 2.8$ \\
Leaf of So (Gmelina arborea Roxb.) & LPC029 & $151.30 \pm 3.1$ \\
Leaf of Kling klang dong (Stephania venosa Spreng.) & PC005 & $146.93 \pm 1.0$ \\
Leaf of Malabar melastome (Melastoma malabathricum L.) & PC052 & $143.45 \pm 4.3$ \\
Leaf of Grape-leaf Wood Rose (Merremia vitifolia Hallier f.) & PC053 & $147.68 \pm 1.8$ \\
\hline
\end{tabular}

acetate extraction. Hydrolysis of $\mathrm{C}_{10} \mathrm{HSL}$ by LPC029 enzyme resulted in releasing HSL as shown by HPLC (Figure 1(c)) compared to standard HSL (Figure $1(\mathrm{a})$ ) and $\mathrm{C}_{10} \mathrm{HSL}$ substrate alone (Figure $1(\mathrm{~b})$ ). Therefore the HSL-degrading enzyme from LPC029 was proven to be HSL-acylase according to the deacylation activity to break the amide bond of $\mathrm{C}_{10} \mathrm{HSL}$, out of which HSL was released as an end product. The substrate $\left(\mathrm{C}_{10} \mathrm{HSL}\right)$ was incompletely hydrolyzed (Figure 1(c)) due to an insufficient amount of enzyme used in the assay. HSL-acylase has been explored in (i) Gramnegative bacteria including Comamonas strain D1 [9], Pseudomonas aeruginosa PAO1 [30], P. aeruginosa PAI-A [31], P. syringae [32], Ralstonia solanacearum GMI1000 [33], Shewanella sp. strain MIB 015 [7], Tenacibaculum maritimum [34], and Variovorax paradoxus VAI-C [25]; (ii) Grampositive bacteria including Rhodococcus erythropolis strain W2 [35] and Streptomyces sp. M664 [8]; and (iii) cyanobacteria such as Anabaena sp. PCC 7120 [36]. Comparison of HSL-acylase activity among these HSL-degrading microbes is difficult due to the difference of both quantitative and qualitative measurement methods. Nevertheless, substrate specificity of the enzymes could be compared qualitatively.
Although the enzymes were derived from a variety of microorganisms, most of HSL-acylases were active against HSL with the carbon chain less than 8 atoms [10]. Testing of the partial purified enzyme from LPC029 with various HSL substrates showed the ability to degrade medium-tolong chains of HSL $\left(\mathrm{C}_{6}-\mathrm{C}_{12}\right)$ in which $\mathrm{C}_{10}$ HSL was the most preferred substrate (Figure 2 ). The activity of this enzyme was not dependent on the substitution of oxo-group on the third carbon atom (Figure 2) which showed no significant difference between two substrates, $\mathrm{C}_{6} \mathrm{HSL}$ and 3-oxo- $\mathrm{C}_{6} \mathrm{HSL}$ $(P \geq 0.05)$. The results suggested the high possibility of LPC029 HSL-acylase in inhibiting QS of medium-chain HSLs dependent on Pcc (3-oxo- $\mathrm{C}_{6} \mathrm{HSL}, 3$-oxo- $\left.\mathrm{C}_{8} \mathrm{HSL}\right)$ and Burkholderia cepacia ( $\mathrm{C}_{6} \mathrm{HSL}, \mathrm{C}_{8} \mathrm{HSL}$ ) and might provide the most effective quenching agent against long-chain HSLs produced by Vibrio anguillarum $\left(\mathrm{C}_{10} \mathrm{HSL}\right)$ and $P$. aeruginosa ( $\left.\mathrm{C}_{12} \mathrm{HSL}\right)$.

3.3. Effect of LPC029 HSL-Degrading Enzyme on Pathogenicity. In vitro efficacy of HSL-degrading enzyme from LPC029 to quench QS-regulated functions was determined by $P e c$ tobacterium carotovorum ssp. carotovorum (Pcc) mediated 


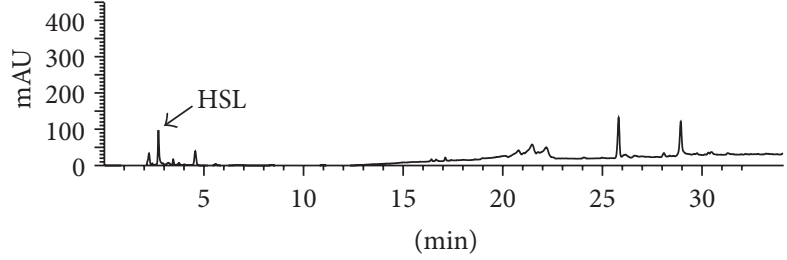

(a)

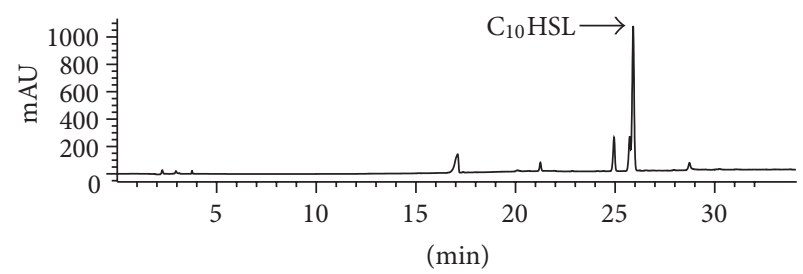

(b)

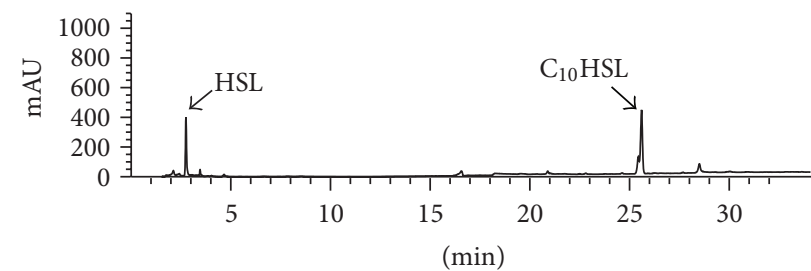

(c)

Figure 1: HPLC analysis of enzymatic hydrolysis product of $\mathrm{C}_{10} \mathrm{HSL}$ with the HSL-degrading enzyme from LPC029. The initial $\mathrm{C}_{10} \mathrm{HSL}$ $(35 \mathrm{mM})$ was reacted with partially purified enzyme from LPC029 for $16 \mathrm{~h}$ and separated with HPLC. HPLC profiles of (a) HSL standard (3.5 mM); (b) unreacted $\mathrm{C}_{10} \mathrm{HSL}(35 \mathrm{mM})$; and (c) reaction product of $\mathrm{C}_{10} \mathrm{HSL}$ with LPC029 HSL-degrading enzyme. The product peak was eluted at $2.8 \mathrm{~min}$. $\mathrm{mAU}$ is the abbreviation for milli-absorbance unit.

soft-rotting potato tuber assay. In $P c c$, the virulence and pathogenicity are QS dependent, but different strains of this subspecies prefer different signal molecules and they are divided into two groups. One group used 3-oxo- $\mathrm{C}_{6} \mathrm{HSL}$ as a predominant signal molecules, whereas another group exploited mainly 3-oxo- $\mathrm{C}_{8} \mathrm{HSL}$ as HSL-dependent QS [37]. Inoculation of $P c c\left(10^{3}\right.$ cells per tuber) evidently resulted in tissue maceration. The addition of $2 \mu \mathrm{g}$ of partially purified HSL-acylase resulted in a statistically significant reduction in soft-rot weight $(P<0.05)$ as shown in Figure 3(e). In the control experiment, neither NSS nor HSL-acylase inoculation induced soft rot in plant tissue (Figures 3(a) and 3(d), resp.). Inoculation of $P c c$ alone $\left(10^{3}\right.$ cells) caused the highest plant tissue necrosis (Figure 3(b)) with the highest soft-rot weight (Figure 3(e)). When the same number of Pcc $\left(10^{3}\right.$ cells) was mixed with $2 \mu \mathrm{g}$ of HSL-acylase before inoculation, the enzyme attenuated the bacterial pathogenicity by reduction of plant tissue necrosis (Figure 3(c)) and caused reduction of soft-rot weight (Figure 3(e)). Several studies have shown the effectiveness of QS targeting strategy in reducing virulence of $P$. aeruginosa [38], Enterobacteriaceae [39], B. cepacia [40], P. carotovorum [23, 41, 42], Serratia liquefaciens [43], Agrobacterium tumefaciens [23], and some aquatic consortia [44]. These results offer an alternative strategy to alternate virulence of plant pathogen using QS-degrading enzyme from endophytic Streptomyces. Due to its ability to degrade long-chain HSL with moderate activity toward short-chain HSL, the QQE from Streptomyces LPC029 might be of interest to control certain plant and human pathogens. However, more in-depth in vitro and also in vivo investigations are warranted.

\section{Conclusion}

The HSL-degrading activity among rhizospheric and endophytic actinomycetes was assessed and the latter was found

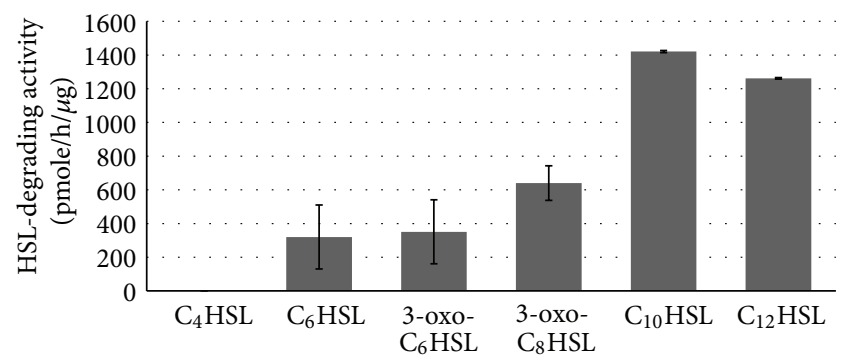

FIGURE 2: Substrate specificity of LPC029 HSL-degrading enzyme. Partially purified enzyme was mixed with each of HSLs. The activity was determined based on HSL leftover on C. violaceum CV026 and A. tumefaciens NTL4 (pZLR4) bioassay plates. Relative activity is given in parenthesis. Bars indicate SD values of four replicates.

to possess this enzyme activity at higher frequency than the soil isolates. It is interesting to note that this study was the first report on studying the distribution of HSL-degrading enzyme in actinomycetes as well as the first report on finding such an activity in endophytic actinomycetes. Endophytic Streptomyces LPC029 showed the highest $\mathrm{C}_{10} \mathrm{HSL}$-degrading activity at $151.30 \pm 3.1 \mathrm{nmole} / \mathrm{h} / \mathrm{mL}$ and its enzyme showed broad substrate specificity against medium-to-long-chain HSLs. The enzyme was classified as HSL-acylase which hydrolyzes an amide bond between an acyl-side chain and a homoserine lactone and releases a free HSL. The partially purified enzyme from LPC029 attenuated soft-rot diseases caused by Pcc, which made the strain as well as many other QQ actinomycetes in this study potential candidates for biocontrol against QS-dependent phytopathogens. Further study on growth conditions including nutrients, temperature, $\mathrm{pH}$, and aerations is required to maximize enzyme productivity in the selected strain(s). 


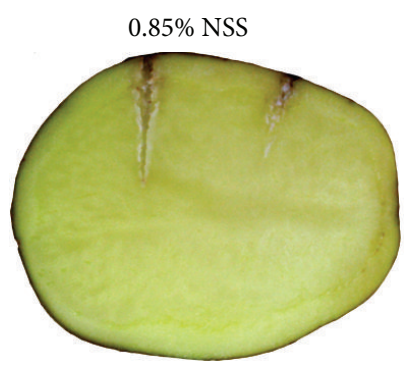

(a)

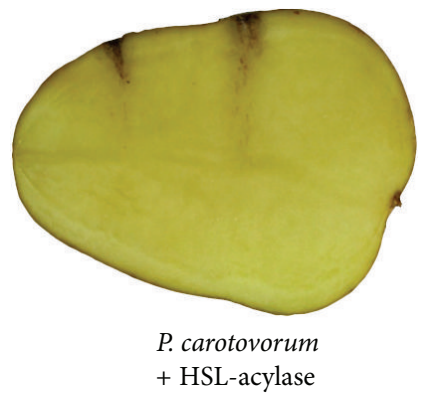

(c)

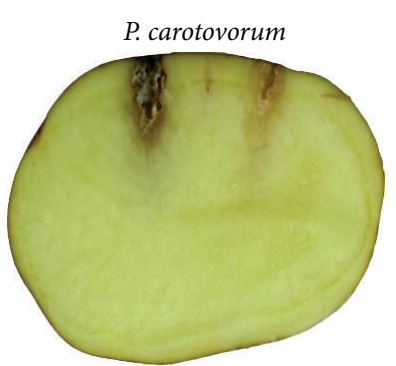

(b)

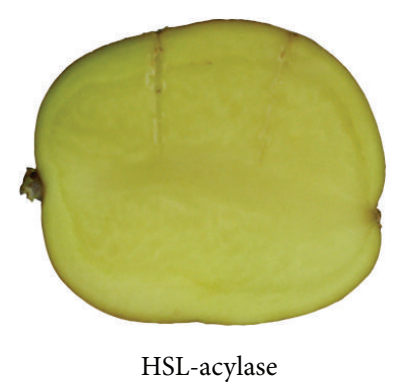

(d)

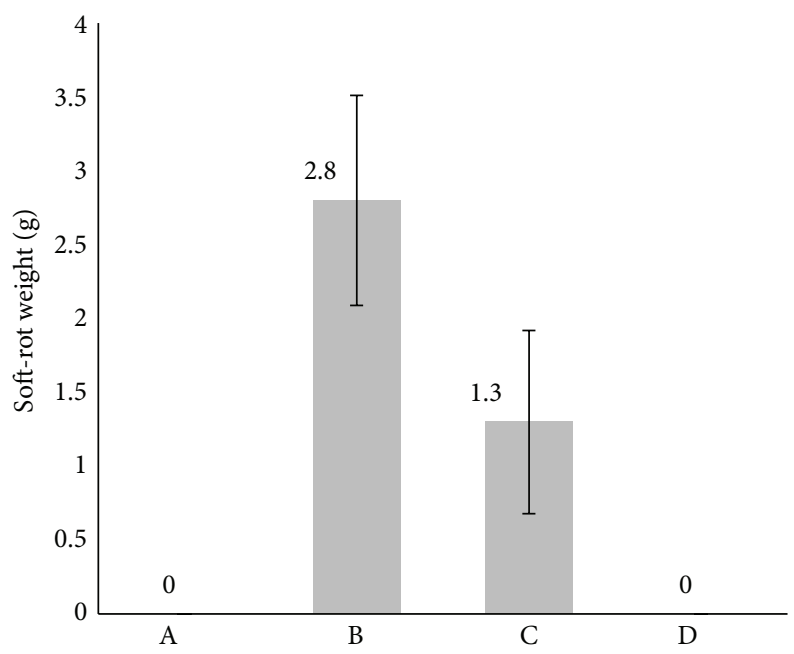

(e)

Figure 3: Effects of LPC029 HSL-degrading enzyme on pathogenicity of Pcc on potato tubers. Pathogenicity of Pcc was determined by inspection of lesion zones induced upon inoculation of potato tuber at two different sites. (a) Negative control consisting of tuber treated with $0.85 \%$ NSS, (b) inoculation of Pcc alone at $10^{3}$ cells per tuber, (c) inoculation of $P c c$ at $10^{3}$ cells mixed with $2 \mu \mathrm{g}$ of partial purified HSLacylase per tuber, (d) $2 \mu \mathrm{g}$ of partially purified HSL-acylase, and (e) pathogenicity of Pcc determined by soft-rot weight. Soft-rot tissue from treatment (a)-(d) was measured after inoculation of Pcc for 3 days; bars indicate SD values of four replicates.

\section{Acknowledgments}

This work was supported by the MRG5180031 Grant of the Thailand Research Fund (TRF) and the Commission on Higher Education (CHE) and supported in part by the Center of Excellence on Agricultural Biotechnology, Science and Technology Postgraduate Education and Research Development Office, Office of Higher Education Commission, Ministry of Education (AG-BIO/PERDO-CHE). The authors thank Dr. Tavan Janvilisri and Dr. Pahol Kosiyachinda for critical reading of the paper.

\section{References}

[1] D. Chadwick and J. Goode, Antibiotic Resistance: Origins, Evolution, Selection, and Spread, John Wiley and Sons, New York, NY, USA, 1997.

[2] A. E. Clatworthy, E. Pierson, and D. T. Hung, "Targeting virulence: a new paradigm for antimicrobial therapy," Nature Chemical Biology, vol. 3, no. 9, pp. 541-548, 2007.

[3] M. B. Miller and B. L. Bassler, "Quorum sensing in bacteria," Annual Review of Microbiology, vol. 55, pp. 165-199, 2001.

[4] N. A. Whitehead, A. M. L. Barnard, H. Slater, N. J. L. Simpson, and G. P. C. Salmond, "Quorum-sensing in Gram-negative 
bacteria," FEMS Microbiology Reviews, vol. 25, no. 4, pp. 365404, 2006.

[5] S. C. Winans, "Command, control and communication in bacterial pathogenesis," Trends in Microbiology, vol. 6, no. 10, pp. 382-383, 1998.

[6] Y. H. Dong, J. L. Xu, X. Z. Li, and L. H. Zhang, "AiiA, an enzyme that inactivates the acylhomoserine lactone quorum-sensing signal and attenuates the virulence of Erwinia carotovora," Proceedings of the National Academy of Sciences of the United States of America, vol. 97, no. 7, pp. 3526-3531, 2000.

[7] T. Morohoshi, S. Nakazawa, A. Ebata, N. Kato, and T. Ikeda, "Identification and characterization of $\mathrm{N}$-acylhomoserine lactone-acylase from the fish intestinal Shewanella sp. strain MIB015," Bioscience, Biotechnology and Biochemistry, vol. 72, no. 7, pp. 1887-1893, 2008.

[8] S. Y. Park, H. O. Kang, H. S. Jang, J. K. Lee, B. T. Koo, and D. Y. Yum, "Identification of extracellular $N$-acylhomoserine lactone acylase from a Streptomyces sp. and its application to quorum quenching," Applied and Environmental Microbiology, vol. 71, no. 5, pp. 2632-2641, 2005.

[9] S. Uroz, P. Oger, S. R. Chhabra, M. Cámara, P. Williams, and Y. Dessaux, " $N$-acyl homoserine lactones are degraded via an amidolytic activity in Comamonas sp. strain D1," Archives of Microbiology, vol. 187, no. 3, pp. 249-256, 2007.

[10] K. W. Hong, C. L. Koh, C. K. Sam, W. F. Yin, and K. G. Chan, "Quorum quenching revisited-from signal decays to signalling confusion," Sensors, vol. 12, no. 4, pp. 4661-4696, 2012.

[11] I. Saadoun, R. Rawashdeh, T. Dayeh, Q. Ababneh, and A. Mahasneh, "Isolation, characterization and screening for fiber hydrolytic enzymes-producing streptomycetes of Jordanian forest soils," Biotechnology, vol. 6, no. 1, pp. 120-128, 2007.

[12] H. Tan, Z. Deng, and L. Cao, "Isolation and characterization of actinomycetes from healthy goat faeces," Letters in Applied Microbiology, vol. 49, no. 2, pp. 248-253, 2009.

[13] A. T. Bull, M. Goodfellow, and J. H. Slater, "Biodiversity as a source of innovation in biotechnology," Annual Review of Microbiology, vol. 46, pp. 219-252, 1992.

[14] M. Anupama, K. J. P. Narayana, and M. Vijayalakshmi, "Screening of Streptomyces purpeofuscus for antimicrobial metabolites," Research Journal of Microbiology, vol. 2, no. 12, pp. 992-994, 2007.

[15] C. Cha, P. Gao, Y. C. Chen, P. D. Shaw, and S. K. Farrand, "Production of acyl-homoserine lactone quorum-sensing signals by gram-negative plant-associated bacteria," Molecular PlantMicrobe Interactions, vol. 11, no. 11, pp. 1119-1129, 1998.

[16] K. H. McClean, M. K. Winson, L. Fish et al., "Quorum sensing and Chromobacterium violaceum: exploitation of violacein production and inhibition for the detection of $\mathrm{N}$-acylhomoserine lactones," Microbiology, vol. 143, no. 12, pp. 3703-3711, 1997.

[17] M. D. Chilton, T. C. Currier, and S. K. Farrand, "Agrobacterium tumefaciens DNA and PS8 bacteriophage DNA not detected in crown gall tumors," Proceedings of the National Academy of Sciences of the United States of America, vol. 71, no. 9, pp. 36723676, 1974.

[18] D. J. Lane, "16S/23S rRNA sequencing," in Nucleic Acid Techniques in Bacterial Systematics, E. Stackerbrand and M. Goodfellow, Eds., John Wiley and Sons, 1991.

[19] F. Sanger, S. Nicklen, and A. R. Coulson, "DNA sequencing with chain-terminating inhibitors," Proceedings of the National Academy of Sciences of the United States of America, vol. 74, no. 12, pp. 5463-5467, 1977.
[20] T. Burr, A. M. L. Barnard, M. J. Corbett, C. L. Pemberton, N. J. L. Simpson, and G. P. C. Salmond, "Identification of the central quorum sensing regulator of virulence in the enteric phytopathogen, Erwinia carotovora: The VirR repressor," Molecular Microbiology, vol. 59, no. 1, pp. 113-125, 2006.

[21] J. G. Holt, N. R. Krieg, P. H. A. Sneath, J. T. Staley, and S. T. Williams, Bergey's Manual of Determinative Bacteriology, Lippincott Williams \& Wilkins, Hagerstown, Md, USA, 1994.

[22] S. J. Lee, S. Y. Park, J. J. Lee, D. Y. Yum, B. T. Koo, and J. K. Lee, "Genes encoding the $N$-acyl homoserine lactonedegrading enzyme are widespread in many subspecies of Bacillus thuringiensis," Applied and Environmental Microbiology, vol. 68, no. 8, pp. 3919-3924, 2002.

[23] L. Molina, F. Constantinescu, L. Michel, C. Reimmann, B. Duffy, and G. Défago, "Degradation of pathogen quorum-sensing molecules by soil bacteria: a preventive and curative biological control mechanism," FEMS Microbiology Ecology, vol. 45, no. 1, pp. 71-81, 2003.

[24] G. Strobel, "Harnessing endophytes for industrial microbiology," Current Opinion in Microbiology, vol. 9, no. 3, pp. 240-244, 2006.

[25] J. R. Leadbetter and E. P. Greenberg, "Metabolism of acylhomoserine lactone quorum-sensing signals by Variovorax paradoxus," Journal of Bacteriology, vol. 182, no. 24, pp. 69216926, 2000.

[26] Y. H. Dong and L. H. Zhang, "Quorum sensing and quorumquenching enzymes," Journal of Microbiology, vol. 43, pp. 101109, 2005.

[27] M. Rosenblueth and E. Martínez-Romero, "Bacterial endophytes and their interactions with hosts," Molecular PlantMicrobe Interactions, vol. 19, no. 8, pp. 827-837, 2006.

[28] R. P. Ryan, K. Germaine, A. Franks, D. J. Ryan, and D. N. Dowling, "Bacterial endophytes: recent developments and applications," FEMS Microbiology Letters, vol. 278, no. 1, pp. 1-9, 2008.

[29] G. Strobel and B. Daisy, "Bioprospecting for microbial endophytes and their natural products," Microbiology and Molecular Biology Reviews, vol. 67, no. 4, pp. 491-502, 2003.

[30] J. J. Huang, A. Petersen, M. Whiteley, and J. R. Leadbetter, "Identification of QuiP, the product of gene PA1032, as the second acyl-homoserine lactone acylase of Pseudomonas aeruginosa PAO1," Applied and Environmental Microbiology, vol. 72, no. 2, pp. 1190-1197, 2006.

[31] J. J. Huang, J. I. Han, L. H. Zhang, and J. R. Leadbetter, "Utilization of acyl-homoserine lactone quorum signals for growth by a soil Pseudomonad and Pseudomonas aeruginosa PAO1," Applied and Environmental Microbiology, vol. 69, no. 10, pp. 5941-5949, 2003.

[32] R. W. Shepherd and S. E. Lindow, "Two dissimilar $N$-aeylhomoserine lactone acylases of Pseudomonas syringae influence colony and biofilm Morphology," Applied and Environmental Microbiology, vol. 75, no. 1, pp. 45-53, 2009.

[33] C. N. Chen, C. J. Chen, C. T. Liao, and C. Y. Lee, "A probable aculeacin A acylase from the Ralstonia solanacearum GMI1000 is $N$-acyl-homoserine lactone acylase with quorum-quenching activity," BMC Microbiology, vol. 9, article 89, 2009.

[34] M. Romero, R. Avendaño-Herrera, B. Magariños, M. Cámara, and A. Otero, "Acylhomoserine lactone production and degradation by the fish pathogen Tenacibaculum maritimum, a member of the Cytophaga-Flavobacterium-Bacteroides (CFB) group," FEMS Microbiology Letters, vol. 304, no. 2, pp. 131-139, 2010. 
[35] S. Uroz, S. R. Chhabra, M. Cámara, P. Williams, P. Oger, and Y. Dessaux, "N-acylhomoserine lactone quorum-sensing molecules are modified and degraded by Rhodococcus erythropolis W2 by both amidolytic and novel oxidoreductase activities," Microbiology, vol. 151, no. 10, pp. 3313-3322, 2005.

[36] M. Romero, S. P. Diggle, S. Heeb, M. Cámara, and A. Otero, "Quorum quenching activity in Anabaena sp. PCC 7120: identification of AiiC, a novel AHL-acylase," FEMS Microbiology Letters, vol. 280, no. 1, pp. 73-80, 2008.

[37] S. Jafra, H. Jalink, R. Van Der Schoor, and J. M. Van Der Wolf, "Pectobacterium carotovorum subsp. carotovorum strains show diversity in production of and response to $\mathrm{N}$-acyl homoserine lactones," Journal of Phytopathology, vol. 154, no. 11-12, pp. 729739, 2006.

[38] C. F. Sio, L. G. Otten, R. H. Cool et al., "Quorum quenching by an $N$-acyl-homoserine lactone acylase from Pseudomonas aeruginosa PAO1," Infection and Immunity, vol. 74, no. 3, pp. 1673-1682, 2006.

[39] L. Ravn Flodgaard, A. B. Christensen, S. Molin, M. Givskov, and L. Gram, "Influence of food preservation parameters and associated microbiota on production rate, profile and stability of acylated homoserine lactones from food-derived Enterobacteriaceae," International Journal of Food Microbiology, vol. 84, no. 2, pp. 145-156, 2003.

[40] C. Aguilar, I. Bertani, and V. Venturi, "Quorum-sensing system and stationary-phase sigma factor $(r p o S)$ of the onion pathogen Burkholderia cepacia genomovar I type strain, ATCC 25416," Applied and Environmental Microbiology, vol. 69, no. 3, pp. 1739-1747, 2003.

[41] Y. H. Dong, L. H. Wang, J. L. Xu, H. B. Zhang, X. F. Zhang, and L. H. Zhang, "Quenching quorum-sensing-dependent bacterial infection by an $N$-acyl homoserine lactonase," Nature, vol. 411, no. 6839, pp. 813-817, 2001.

[42] Y. H. Dong, X. F. Zhang, J. L. Xu, and L. H. Zhang, "Insecticidal Bacillus thuringiensis Silences Erwinia carotovora virulence by a new form of microbial antagonism, signal interference," Applied and Environmental Microbiology, vol. 70, no. 2, pp. 954-960, 2004.

[43] T. Hjelmgaard, T. Persson, T. B. Rasmussen, M. Givskov, and J. Nielsen, "Synthesis of furanone-based natural product analogues with quorum sensing antagonist activity," Bioorganic and Medicinal Chemistry, vol. 11, no. 15, pp. 3261-3271, 2003.

[44] F. Xu, T. Byun, H. J. Deussen, and K. R. Duke, "Degradation of $\mathrm{N}$-acylhomoserine lactones, the bacterial quorum-sensing molecules, by acylase," Journal of Biotechnology, vol. 101, no. 1, pp. 89-96, 2003. 

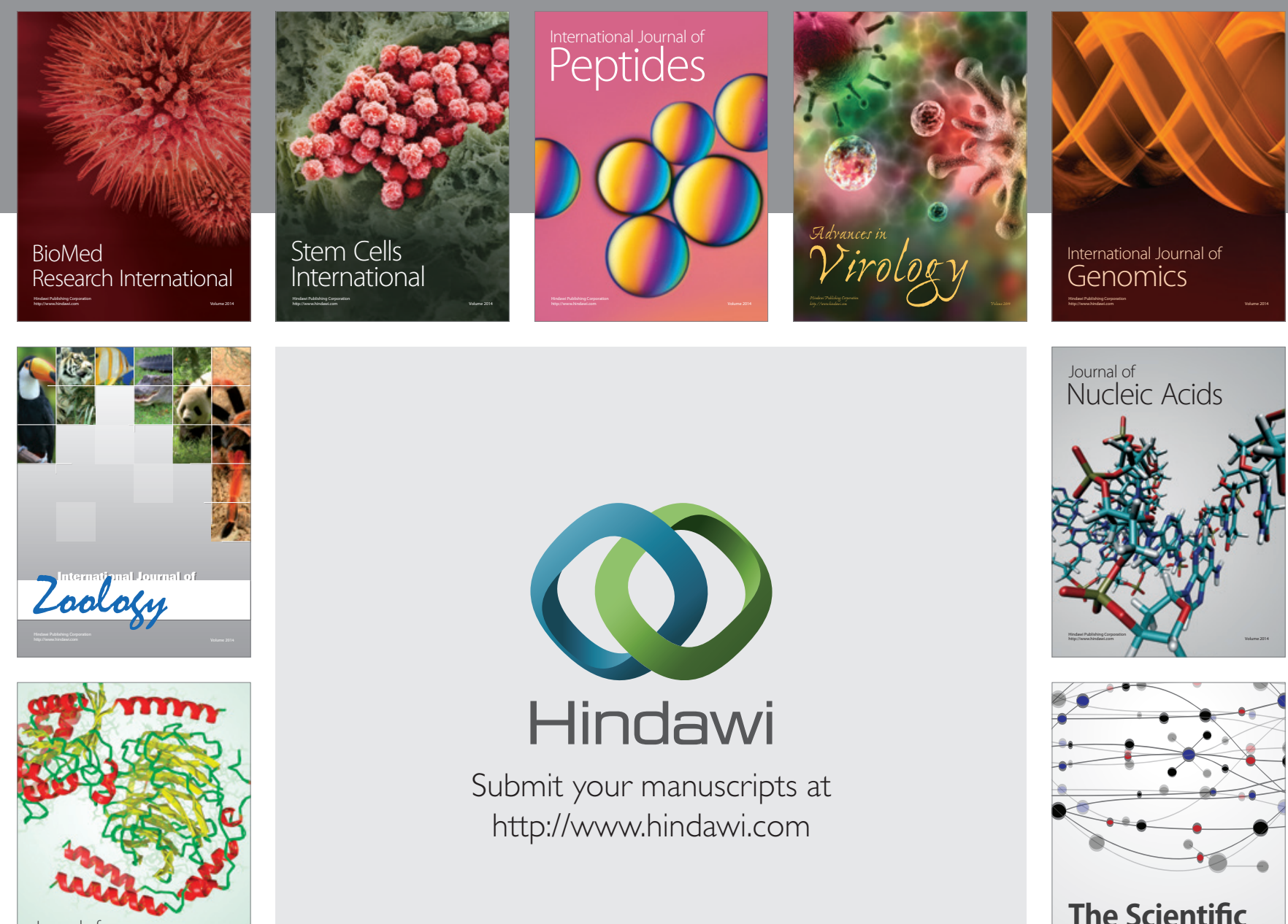

Submit your manuscripts at

http://www.hindawi.com

Journal of
Signal Transduction
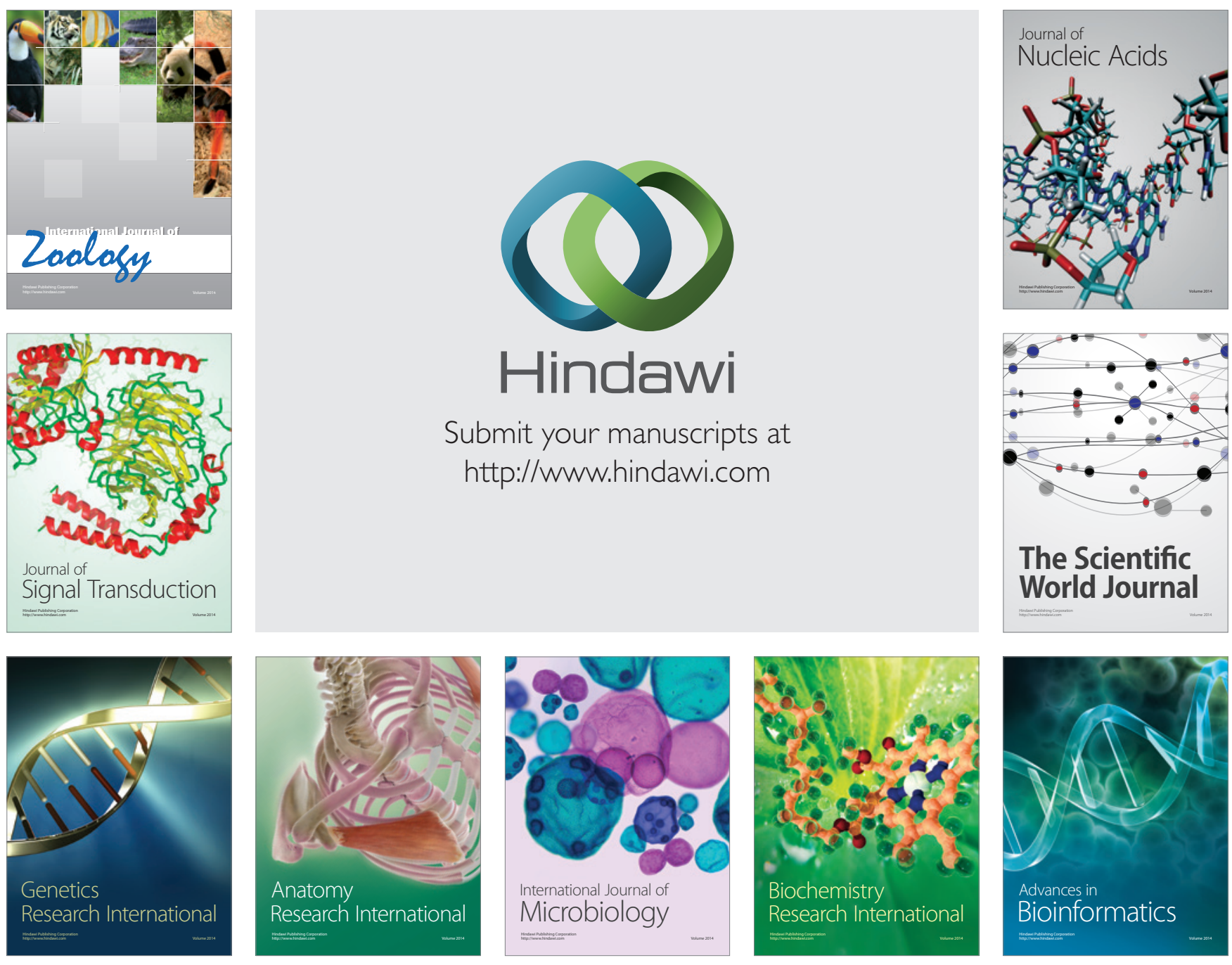

The Scientific World Journal
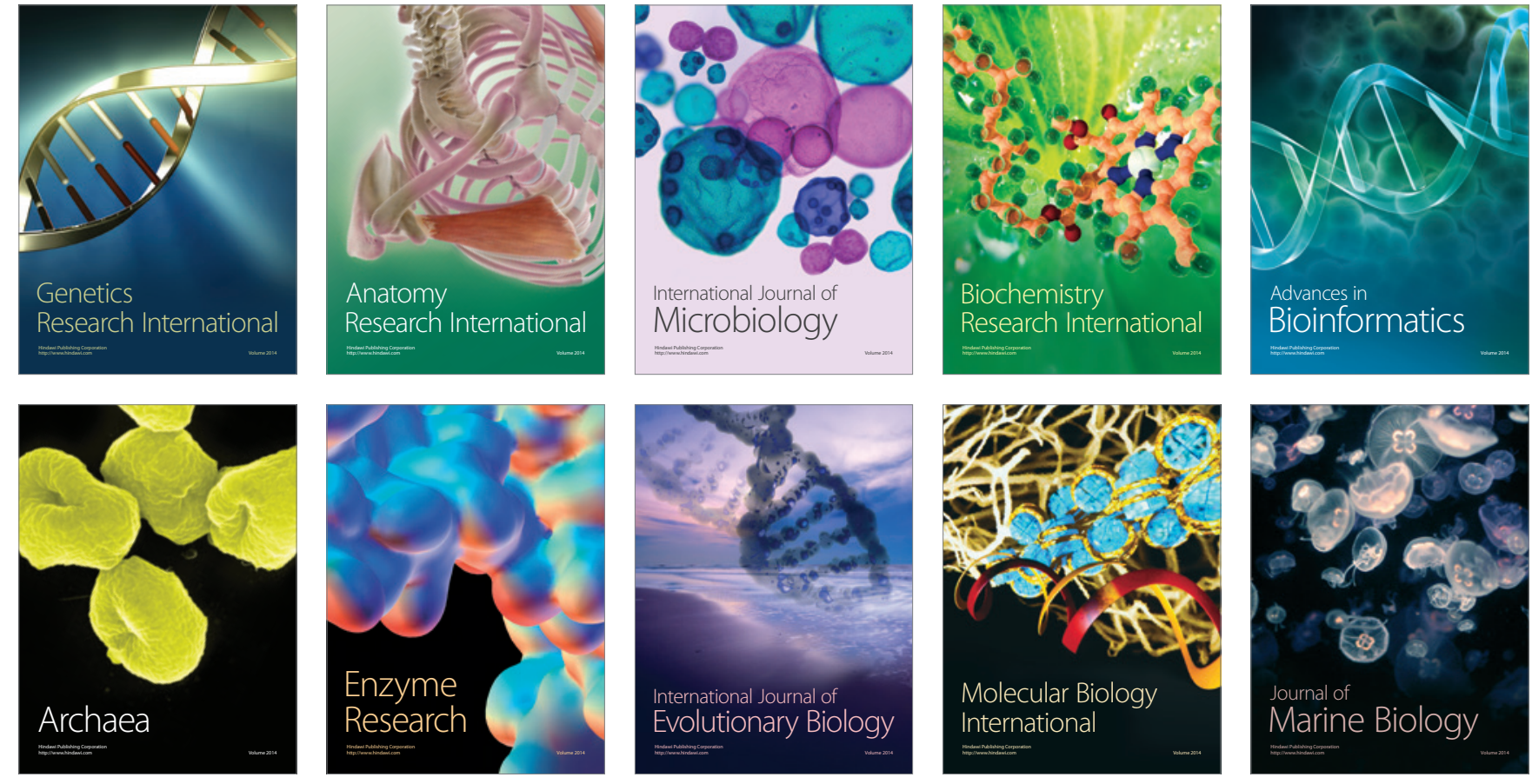